East Tennessee State University

Digital Commons@ East Tennessee State University

ETSU Faculty Works

Faculty Works

8-19-2016

\title{
Using Scientific Inquiry to Increase Knowledge of Vaccine Theory and Infectious Diseases
}

Zachary Walls

East Tennessee State University, wallsz@etsu.edu

John B. Bossaer

East Tennessee State University, bossaer@etsu.edu

David Cluck

East Tennessee State University, cluckd@etsu.edu

Follow this and additional works at: https://dc.etsu.edu/etsu-works

Part of the Medical Education Commons, Pharmacy and Pharmaceutical Sciences Commons, and the Public Health Commons

\section{Citation Information}

Walls, Zachary; Bossaer, John B.; and Cluck, David. 2016. Using Scientific Inquiry to Increase Knowledge of Vaccine Theory and Infectious Diseases. Education for Health. Vol.29(2). 95-106. https:// doi.org/10.4103/1357-6283.188743 ISSN: 1469-5804

This Article is brought to you for free and open access by the Faculty Works at Digital Commons @ East Tennessee State University. It has been accepted for inclusion in ETSU Faculty Works by an authorized administrator of Digital Commons @ East Tennessee State University. For more

information, please contact digilib@etsu.edu. 


\section{Using Scientific Inquiry to Increase Knowledge of Vaccine Theory and Infectious Diseases}

\section{Copyright Statement}

(C) 2016 Education for Health. This document was originally published in the Education for Health. 


\title{
Using Scientific Inquiry to Increase Knowledge of Vaccine Theory and Infectious Diseases
}

\author{
Zachary F. Walls ${ }^{1,2}$, John B. Bossaer ${ }^{3}$, David Cluck ${ }^{2,3}$ \\ Departments of 'Pharmaceutical Sciences and ${ }^{3}$ Pharmacy Practice, Gatton College of Pharmacy, East Tennessee State University, ${ }^{2}$ Center of \\ Excellence for Inflammation, Infectious Disease and Immunity, Johnson City, TN, USA
}

\begin{abstract}
Background: The aim of this study was to design and evaluate a laboratory activity based on scientific inquiry to educate first-year pharmacy students in the U.S. about vaccination theory and the attributes of common pathogens. Methods: The laboratory activity had two principal sections. The first consisted of an interactive game during which students rolled a die to determine outcomes based on a set of pre-determined criteria. In the second section, students generated and tested hypotheses about vaccine theory using a computer simulation that modeled disease transmission within a large population. In each section students were asked to evaluate epidemiological data and make inferences pertinent to vaccination effectiveness. Results: Mean scores on a knowledge-based assessment given immediately before and immediately after the activity increased from $46 \%$ to $71 \%$. Discussion: A laboratory activity designed to stimulate scientific inquiry within pharmacy students enabled them to increase their knowledge of common vaccines and infectious diseases.
\end{abstract}

Keywords: Active learning, computer simulation, laboratory activity, pharmacy students, role-playing game

\section{Background}

Vaccines represent one of the crowning achievements of medical technology..$^{[1]}$ The development of vaccines has reduced the incidence of infection by a myriad of pathogens that until recently had plagued society throughout recorded history. ${ }^{[2]}$ And yet, admiration and adoption of vaccines is not universal. This is due in part to their unique position in the pharmaceutical landscape, and, unfortunately, in part to popular misconceptions linking vaccines to various maladies, including autism. ${ }^{[3]}$ In the United States, pharmacists administer many vaccines to the public and thus must be properly informed so that they can discuss the risks and benefits of vaccines with their patients. ${ }^{[4]}$

\begin{tabular}{|l|l|}
\hline \multicolumn{2}{|c|}{ Access this article online } \\
\hline Quick Response Code: & Website: \\
\hline & www.educationforhealth.net \\
\cline { 2 - 2 } & \\
\hline
\end{tabular}

\footnotetext{
Address for correspondence:

Dr. Zachary F. Walls, Department of Pharmaceutical Sciences, Gatton College of Pharmacy, East Tennessee State University, P. 0. Box 70594, Johnson City, TN 37614, USA.

E-mail: wallsz@etsu.edu
}

It is also important to encourage and fortify the scientific literacy of student pharmacists. In the U.S., all pharmacists entering practice must possess a Doctorate of Pharmacy (PharmD) degree. This degree is conferred following successful completion of a four-year program during which students receive didactic instruction in basic, pharmaceutical, and clinical sciences, as well as experiential education in multiple settings (hospital, community, etc.). Due to the ever-expanding catalog of medicinal drugs and the particulars associated with their therapeutic applications, the PharmD curriculum often requires a reduction in time devoted to scientific inquiry and experimentation for the sake of didactic instruction. This paradigm generally results in pharmacists being experts in the facts of pharmaceutical therapy but not being clinicians capable of investigating complex problems. The laboratory environment, due to its physical and temporal properties, has the potential for dissemination of information via scientific inquiry. The goal of the laboratory exercise described herein was to educate students on vaccine

This is an open access article distributed under the terms of the Creative Commons Attribution-NonCommercial-ShareAlike 3.0 License, which allows others to remix, tweak, and build upon the work non-commercially, as long as the author is credited and the new creations are licensed under the identical terms.

For reprints contact: reprints@ medknow.com

How to cite this article: Walls ZF, Bossaer JB, Cluck D. Using scientific inquiry to increase knowledge of vaccine theory and infectious diseases. Educ Health 2016;29:95-106. 
effectiveness and herd immunity by using the basic tenets of the scientific method.

This goal is highly significant in relation to the standards put forth by the agency responsible for pharmacy school accreditation in the U.S., the Accreditation Council for Pharmacy Education (ACPE). ${ }^{[5]}$ The 2016 standards state that content areas such as the "properties of microorganisms responsible for human disease", the "augmentation of the human immune system to prevent disease", and the "cause and effect patterns of health and disease in large populations" are central to a "contemporary, high quality pharmacy education". This laboratory experience represents an innovative implementation of these standards.

There is a body of literature on inquiry-based laboratory exercises, although most published exercises have been designed for the undergraduate level. ${ }^{[6]}$ Several reports dealing specifically with inquiry-based education in pharmacy education have also been published, though largely in the context of didactic instruction. ${ }^{[7,8]}$ In addition, a handful of articles detailing the use of laboratory research in the pharmacy curriculum to increase understanding of the scientific method are available. ${ }^{[9,10]}$ All of these articles extoll the virtue of inquiry-based learning and confirm its value in increasing understanding and knowledge retention.

The purpose of this educational innovation and its evaluation was to develop and validate a laboratory exercise that reinforced and augmented instruction on vaccines and their related pathogens covered briefly in other didactic courses in the curriculum, e.g., immunology. The approaches chosen to achieve this goal were guided scientific inquiry and computer-simulated experimentation in order to challenge first year students to use the scientific method to answer complex questions. Guided scientific inquiry refers to activities designed to help students arrive at a specified answer by engaging in scientific processes. ${ }^{[11]}$ These methods are based on the educational principle of social constructivism, which argues that knowledge is constructed in the mind of the learner rather than transferred from the instructor. ${ }^{[12]}$

This laboratory exercise occurs at the end of the spring semester of the first year, approximately 8 months into the curriculum. It was specifically scheduled for this time to take advantage of concepts introduced throughout the first year and to integrate several disciplines, including biopharmaceutics and immunology.

\section{Methods}

The laboratory exercise included 82 students enrolled in their first year of a four-year Doctor of Pharmacy (PharmD) degree program. All students had previously completed 61 credit hours of specified undergraduate courses prior to entering the pharmacy program. The students were divided into two sections for the Integrated Environment for Applied Learning and Skills (IdEALS) course. This course is the second in a 6 course sequence designed to span the length of the didactic PharmD program. The goals of the sequence are to provide an opportunity for hands-on learning and integrate aspects of basic science, pharmaceutical science, and pharmacy practice. Each course within the sequence is assigned 1 credit hour, and each laboratory session typically spans 4 hours once a week.

The vaccine lab consisted of two parts. Part 1 was designed to imitate a role-playing game in which a player's fate is determined by the roll (or rolls) of a die (e.g., Dungeons and Dragons) ${ }^{\left[{ }^{[13]}\right.}$ Dice are small cubes with a different number of dots on each face, ranging from 1 to 6 . They are commonly used in children's games and familiar to all U.S. students. Students were numbered 1 through 6 and then given a single 6-sided die and a laminated note card containing demographic information of a fictitious character [Figure 1]. Additionally, a handout was distributed detailing the rules of the game [Appendix 1]. Based on their number, students were identified as vaccinated or non-vaccinated, and infected or uninfected. Eight scenarios in total were played, with each scenario varying either the pathogen or the percentage of the population vaccinated. Four pathogens were chosen for the exercise: Influenza virus, measles virus, Bordetella pertussis, and Ebola virus. The influenza virus was chosen because the influenza vaccine is the most commonly administered immunization by pharmacists in the U.S. ${ }^{[14]}$ The measles virus was chosen because of measles' highly contagious properties, controversy over the MMR (measles, mumps, and rubella) combined vaccine, and recent outbreaks of measles in the U.S. due to a reduction in vaccine coverage. ${ }^{[15]}$ Bordetella pertussis was chosen for its severity in children and recent U.S. outbreaks. ${ }^{[16]}$ The Ebola virus was chosen for its newsworthiness and its greatly different characteristics compared to the other pathogens chosen. ${ }^{[17]}$

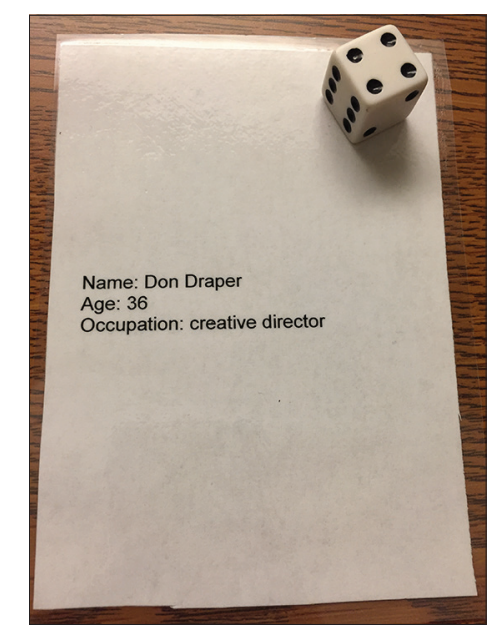

Figure 1: Example of laminated card with fictitious character demographics and die given to each student 
Game play consisted of multiple rounds, with each round containing 2 steps. The first step determined the player's viability (chances of living if infected), which was influenced by the particular pathogen and the character's age. It was calculated by throwing the die three times, and then matching the sum of the rolls to the corresponding variables [Table 1]. The second step was performed between two players and determined whether an infected player passed the pathogen on to an uninfected player. Transmission was influenced by the particular pathogen and the player's vaccination status. It was calculated by throwing each players' die twice, and then matching the sum of their rolls to the corresponding variables [Table 1]. Players continued these 2-step rounds until all pairwise interactions between players had been made.

Following completion of each scenario, students were instructed to enter the results of their character into a cloud-based spreadsheet using a link that had been disseminated via the course's learning management system (Desire 2 Learn) website [Figure 2]. This method of data collection permitted real-time analysis of each variable's effect on various outcomes. For example, as shown in Figure 1, scenarios 1 and 2 compared the outcomes of an influenza virus outbreak when approximately half of the population is vaccinated (scenario 1) versus when approximately 90 percent of the population is vaccinated (scenario 2). These results were used to illustrate the impact of herd immunity and the effectiveness of the influenza vaccine.

Part 2 of the vaccine lab consisted of students using a spreadsheet-based model of disease propagation and vaccine effectiveness. The model used Bayesian probability and estimates of vaccine effectiveness, pathogen mortality, secondary household attack rate, and the duration of infectivity were based on information provided by the U.S. Centers for Disease Control and Prevention (CDC). ${ }^{[18]}$ The model consisted of 10,000 cells representing a closed population of 10,000 individuals. Each cell was designated at random as either "vaccinated" or "unvaccinated" based on the "\% vaccinated" initial condition. The status of individual cells was visualized using conditional formatting. A small percentage of the population (0.1\%) was chosen at random to be "sick". The rate of disease propagation depended on the variables mentioned above as well as a random variable governing interaction between neighboring cells. An example of the visual output of the model for measles virus as a function of percent of the population vaccinated can be seen in Figure 3. The file containing the model, along with a separate file containing instructions on how to modify variable and perform the necessary calculations were distributed via the course's learning management system (Desire 2 Learn) website (Supplementary File).

Students were guided through several different scenarios dealing with the four selected pathogens. With each subsequent scenario, the students were given fewer of the

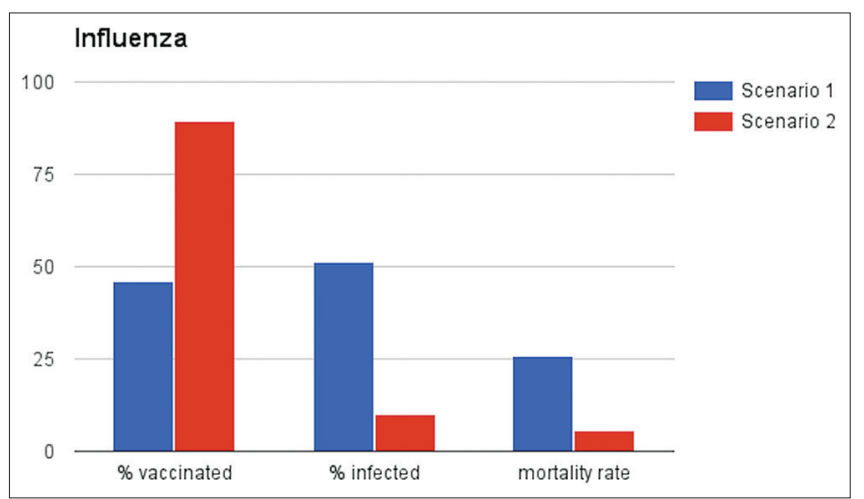

Figure 2: Real time analysis of data entered by students. Each student was assigned an arbitrary number and then asked to record the results of their "character" once the scenario had ended by answering yes $(\mathrm{Y})$ or no $(\mathrm{N})$ to several questions. The graphs were linked to the responses and updated in real time so that results could be discussed and compared as soon as the scenario ended. This graph shows the results of two influenza scenarios. In scenario 1 , approximately half of the participants were vaccinated. In scenario 2 , approximately $90 \%$ of the participants were vaccinated

\begin{tabular}{|c|c|c|c|c|c|c|c|c|}
\hline \multirow[t]{3}{*}{ Steps } & \multicolumn{8}{|c|}{ Pathogen (\%) } \\
\hline & \multicolumn{2}{|c|}{ Influenza virus } & \multicolumn{2}{|c|}{ Measles virus } & \multicolumn{2}{|c|}{ Bordetella pertussis } & \multicolumn{2}{|c|}{ Ebola virus } \\
\hline & Death & Recovery & Death & Recovery & Death & Recovery & Death & Recovery \\
\hline \multicolumn{9}{|l|}{ Step 1: Survival } \\
\hline \multicolumn{9}{|l|}{ Age (years) } \\
\hline 5 & $7(6.9)$ & 8 or $14(16.6)$ & $4(1.4)$ & 5 or $8(12.5)$ & $8(9.7)$ & 4 or $7(8.3)$ & $11(62.5)$ & 15 or $18(5.1)$ \\
\hline$>5-<65$ & $6(4.6)$ & 8 or $14(16.6)$ & $4(1.4)$ & 5 or $8(12.5)$ & $5(2.8)$ & 4 or $7(8.3)$ & $11(62.5)$ & 15 or $18(5.1)$ \\
\hline$\geq 65$ & $7(6.9)$ & 8 or $14(16.6)$ & $4(1.4)$ & 5 or $8(12.5)$ & $8(9.7)$ & 4 or $7(8.3)$ & $11(62.5)$ & 15 or $18(5.1)$ \\
\hline \multicolumn{9}{|c|}{ Step 2: Transmission } \\
\hline \multicolumn{9}{|l|}{ Vaccination status } \\
\hline Vaccinated & \multicolumn{2}{|c|}{9 or less (9.7) } & \multicolumn{2}{|c|}{8 or less (5.4) } & \multicolumn{2}{|c|}{10 or less (15.9) } & \multicolumn{2}{|c|}{7 or less (2.7) } \\
\hline Unvaccinated & \multicolumn{2}{|c|}{11 or less (23.9) } & \multicolumn{2}{|c|}{18 or less (90.3) } & \multicolumn{2}{|c|}{16 or less (76.1) } & \multicolumn{2}{|c|}{9 or less (9.7) } \\
\hline Recovered* & \multicolumn{2}{|c|}{22 or more (1.2) } & \multicolumn{2}{|c|}{ No number (0) } & \multicolumn{2}{|c|}{$24(0.1)$} & \multicolumn{2}{|c|}{ No number (0) } \\
\hline
\end{tabular}




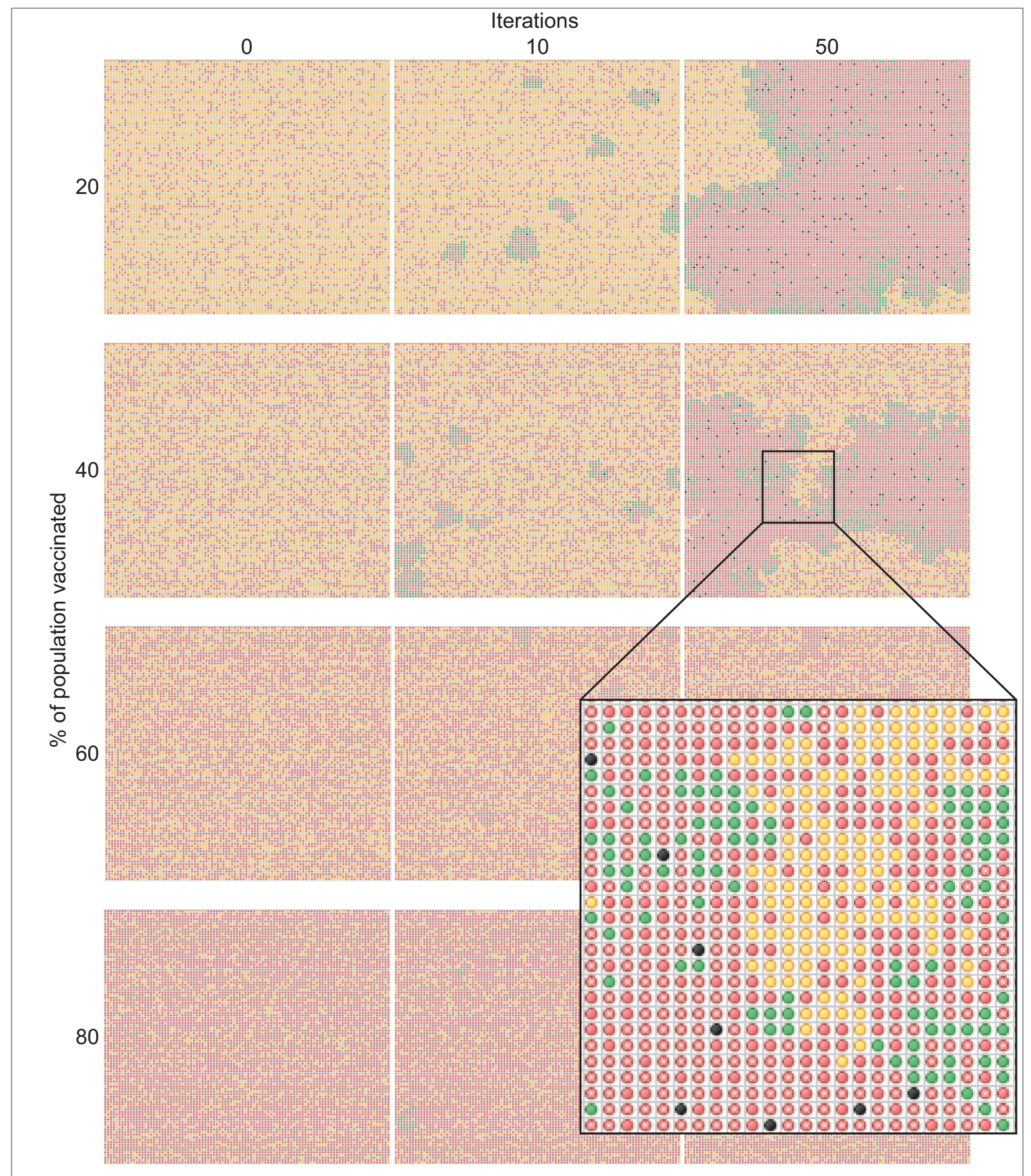

Figure 3: Vaccine computer simulator output. The series of images depict the progression of the measles virus as a function of both time (iterations) and vaccination coverage. The simulation was written in a Microsoft Excel spreadsheet to facilitate manipulation by students. Conditional formatting was used to represent the status of individuals within a population. Green = sick, red = vaccinated, yellow $=$ unvaccinated, black $=$ dead, red with white " $X "$ " recovered from natural infection

starting variables and asked to generate hypotheses about the necessary vaccine effectiveness and/or vaccination rate in order to protect a certain percentage of the population. The students were then able to test their hypotheses by running the simulations and recording the outcomes. All results from the simulation experiments were entered into a separate 
cloud-based spreadsheet so that results could be analyzed in real time [Figure 4]. The real time reporting allowed the instructor to monitor group progress as well as emphasize trends in the data to the entire class.

\section{Program evaluation}

Students were assessed with a knowledge-based multiple choice quiz. Quiz questions were generated by the authors of this study and evaluated for content and consistency by group consensus. The mean scores of the pre-assessment and post-assessment were compared using the paired $t$-test (two-tailed), and the median scores were compared using the Wilcoxon matched-pairs signed-rank test. Both parametric and non-parametric analyses were performed to account for possible non-normally distributed data. All statistical analysis was performed using Prism 6 (GraphPad). Statistical significance for individual questions was determined using McNemar's test $(P<0.05)$. This study was approved as exempt research by the Institutional Review Board of East Tennessee State University.

\section{Results}

To evaluate the effectiveness as this laboratory exercise, students were given a pre-lab assessment at the beginning of the class period and again assessed using the same 15 item tool following completion of the laboratory exercise. Eighty-one students completed the pre-assessment and 82 completed the post-assessment (99\%). Eleven of the 15 knowledge-based assessment questions (73\%) showed a statistically significant improvement in student performance in the post-lab assessment relative to the pre-lab assessment. One question, \#15, showed a statistically significant change

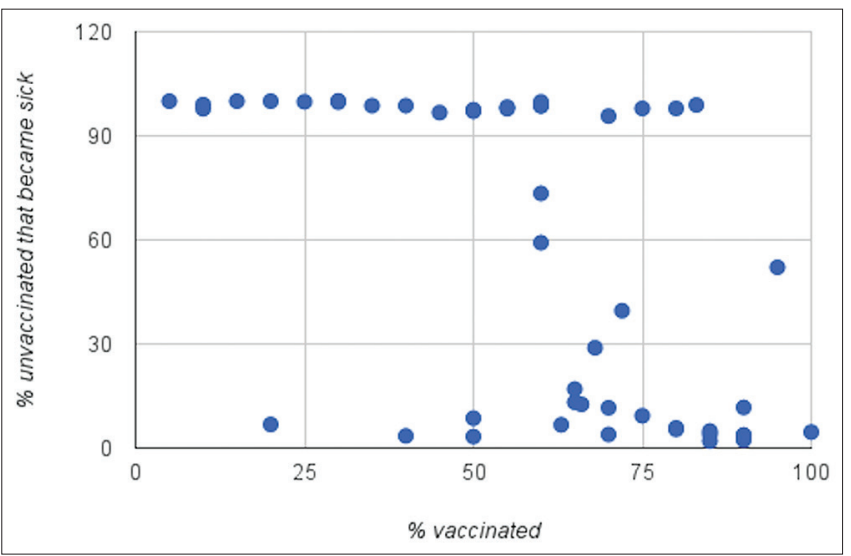

Figure 4: Real time analysis of data entered by students. The chart reflects the results of simulations carried out by students using the computer simulator to identify the optimal level of vaccination against measles in order to protect unvaccinated individuals. Students altered the percent of the population vaccinated against the measles virus and then ran the simulator until the outbreak was contained. Graphs such as this were linked to the responses from the entire class and updated in real time so that the results could be discussed and compared continuously in percent correct, but student performance declined rather than increased. This question, which asked the students to identify the pathogen responsible for the greatest number of U.S. deaths in 2014, was answered in one of the student handouts, but was not emphasized by any of the instructors. In addition, both the mean and median assessment score improved significantly. Of the 81 students that completed both the pre and post assessments, 75 (93\%) had scores that improved (the scores of 3 did not change, and the scores of 3 others decreased) [Table 2].

\section{Discussion}

A strong record of using game play to educate students in the life sciences can be found in the literature. ${ }^{[19]}$ Most reports detail the creation of card or board games, and at least one reports the results of using an interactive video game. ${ }^{[20-22]}$

\begin{tabular}{|c|c|c|c|}
\hline Question & $\begin{array}{c}\text { Preassessment, } \\
\% \text { correct }\end{array}$ & $\begin{array}{c}\text { Postassessment, } \\
\% \text { correct }\end{array}$ & $P$ \\
\hline $\begin{array}{l}\text { 1. Which of the following pathogens } \\
\text { is most contagious? }\end{array}$ & 14 & 65 & $<0.000$ \\
\hline $\begin{array}{l}\text { 2. Which of the following pathogens } \\
\text { is least contagious? }\end{array}$ & 26 & 56 & $<0.000$ \\
\hline $\begin{array}{l}\text { 3. Which of the following vaccines } \\
\text { is most efficacious? }\end{array}$ & 67 & 84 & 0.01 \\
\hline $\begin{array}{l}\text { 4. Which of the following vaccines } \\
\text { is least efficacious? }\end{array}$ & 70 & 74 & 0.52 \\
\hline $\begin{array}{l}\text { 5. Which of the following pathogens } \\
\text { has the highest mortality rate? }\end{array}$ & 48 & 87 & $<0.000$ \\
\hline $\begin{array}{l}\text { 6. Which of the following pathogens } \\
\text { has the lowest mortality rate? }\end{array}$ & 38 & 54 & 0.04 \\
\hline 7. What is herd immunity? & 98 & 100 & 0.25 \\
\hline 8. The influenza vaccine that a & 46 & 59 & 0.05 \\
\hline
\end{tabular}
majority of Americans are vaccinated with is an example of which of the following vaccine strategies?

9. The measles vaccine is an example of which of the following vaccine strategies?

10. The pertussis vaccine is an example of which of the following vaccine strategies?

11. The Ebola vaccines currently in clinical trials are examples of which of the following vaccine strategies?

12. What is the vaccination rate in the US for the flu vaccine?

13. What is the vaccination rate in the US for the measles vaccine?

14. What is the vaccination rate in the US for the pertussis vaccine?

15. Which of the following pathogens was responsible for the greatest number of deaths in the US last year?

Overall score, mean (SD)

$45.6(11.1) \quad 70.6(15.9) \quad<0.0001$

Overall score, median (IQR) $46.6(40.0-53.3) 73.4(60.0-80.0)<0.0001$ 
Evaluations of all of these innovations demonstrate the advantage of using games to increase student understanding and knowledge of complex biological concepts. Additionally, Donohoe and colleagues have described a laboratory exercise that deals exclusively with vaccines. ${ }^{[23-26]}$ The authors report on the implementation and results of a well-designed laboratory exercise that improves students' knowledge of three common vaccines (influenza, pneumococcal, and shingles) and the practical concerns regarding their administration.

The laboratory exercise described above based on game play and computer simulations also significantly increased students' knowledge of facts and statistics related to vaccines. Additionally, it provided an opportunity for students to use the scientific method to test hypotheses. Taking place at the end of their first year of instruction, it took advantage of other topics taught during that year, including immunology and biopharmaceutics.

The students generally appeared to enjoy the laboratory exercise, although this was not assessed formally. Anecdotally, instructors observed that some individuals responded positively to the dice game and caught on to the rules and scoring quite quickly, while others responded to the computer simulation more favorably. As this lab occurred twice (once each for two different sections) with different instructors for each section, it was found that the dice game benefitted from input from a practicing clinical pharmacist who moderated one of the sections. Students seemed to respond enthusiastically as the game was compared to real-life statistics and observations from practice. Conversely, it was found that the computer simulations benefitted from group guidance by the program's author, who moderated the other section. Students were able to receive feedback about their hypotheses with respect to the variables in the program and gain an appreciation for experimental repetition during the section led by the instructor who wrote the code.

Although statistical analysis of pre and post assessments indicated that the students increased their knowledge of the subjects addressed, it is unclear if this increase is permanent, or whether it reflects a transient retention of facts. A longitudinal study would be necessary to ascertain the lasting value of this laboratory exercise.

Given the strong improvement in student assessment scores, the faculty members involved in this course will continue to include this exercise as part of the semester's instruction, however, certain changes and improvements are desired. With respect to the dice game, an additional layer of game theory will be implemented in future years. Game players will be given a finite number of vaccines and must decide as a collective how to distribute them, given the susceptibility to disease and geographical restrictions of certain players. It is anticipated that this will provoke different hypotheses within the group about how best to protect the greatest number of players. The game will then be played out as before with the results recorded and results analyzed to determine the most viable hypothesis.

With respect to the computer simulation, certain changes will be made to the underlying code. For instance, as the code is currently written, the duration of transmissibility competes with the mortality rate as determined by Bayesian probability based on reported values. The models would most likely be more faithful if the chance of death was only calculated after a constant incubation period. For pathogens with a low mortality rate (such as the measles virus), this change will not have a large effect, but for pathogens with a long incubation period and a high mortality rate (such as the Ebola virus), this change could have large ramifications. Additionally, the model will be changed to incorporate demographic information, and random ages will be assigned to each individual and their probabilities for infection and mortality will change based on that assignment. These changes will provide greater value to the lab and enhance the students' understanding of vaccines and public health.

Lastly, although this laboratory exercise was designed primarily for first year pharmacy students, it could be easily adapted for medical students, graduate students studying public health, or undergraduate students studying immunology and microbiology. Knowledge of vaccines and infectious diseases remains important today, and it is critical that the next generation of life scientists and healthcare professionals are properly educated on these subjects so that they may counteract the array of misinformation pervasive in society. Furthermore, educating students at all levels to use the scientific method will help create a scientifically literate populace, an admirable goal in itself.

\section{Acknowledgment}

The authors would like to acknowledge Dr. David Roane, Chair of the Department of Pharmaceutical Sciences, for his general support and encouragement.

\section{Financial support and sponsorship}

This research was supported by gifts to the Bill Gatton College of Pharmacy.

\section{Conflicts of interest}

There are no conflicts of interest.

\section{References}

1. Pulendran B, Ahmed R. Immunological mechanisms of vaccination. Nat Immunol 2011;12:509-17.

2. Scully T. The age of vaccines. Nature 2014;507:S2-3. 
3. Mormann M, Gilbertson C, Milavetz G, Vos S. Dispelling vaccine myths: MMR and considerations for practicing pharmacists. J Am Pharm Assoc 2012;52:e282-6.

4. Edwards N, Gorman Corsten E, Kiberd M, Bowles S, Isenor J, Slayter K, et al. Pharmacists as immunizers: A survey of community pharmacists' willingness to administer adult immunizations. Int $\mathrm{J}$ Clin Pharm 2015;37:292-5.

5. Accreditation Council for Pharmacy Education. Accreditation Standards and Key Elements for the Professional Program in Pharmacy Leading to the Doctor of Pharmacy Degree. Effective July 1, 2016. https://www.acpe-accredit.org/pdf/ Standards2016FINAL pdf. [Last accessed on 2016 Jun 10].

6. Kolkhorst FW, Mason CL, DiPasquale DM, Patterson P, Buono MJ. An inquiry-based learning model for an exercise physiology laboratory course. Adv Physiol Educ 2001;25:117-22.

7. Soltis R, Verlinden N, Kruger N, Carroll A, Trumbo T. Process-oriented guided inquiry learning strategy enhances students' higher level thinking skills in a pharmaceutical sciences course. Am J Pharm Educ 2015;79:11.

8. Brown SD. A process-oriented guided inquiry approach to teaching medicinal chemistry. Am J Pharm Educ 2010;74:121.

9. Vaidean GD, Vansal SS, Moore RJ, Feldman S. Student scientific inquiry in the core curriculum. Am J Pharm Educ 2013;77:176.

10. Ramsauer VP. An elective course to engage pharmacy students in research activities. Am J Pharm Educ 2011;75:138.

11. Furtak EM. The problem with answers: An exploration of guided scientific inquiry teaching. Sci Educ 2006;90:453.

12. Bodner G, Klobuchar M, Geelan D. The many forms of constructivism. J Chem Educ 2001;78:1107.

13. Gygax G, Arneson D. Dungeons \& Dragons. Lake Geneva, WI: Tactical Studies Rule 1974.

14. U.S. Department of Health and Human Services. Annual Pharmacy-Based Influenza and Adult Immunization Survey 2013. National Vaccine Program Office; December 2013.

15. Clemmons NS, Gastanaduy PA, Fiebelkorn AP, Redd SB, Wallace GS; Centers for Disease Control and Prevention (CDC). Measles - United States, January 4-April 2, 2015. MMWR Morb Mortal Wkly Rep 2015;64:373-6.

16. Winter K, Glaser C, Watt J, Harriman K; Centers for Disease
Control and Prevention (CDC). Pertussis epidemic - California 2014. MMWR Morb Mortal Wkly Rep 2014;63:1129-32.

17. Incident Management System Ebola Epidemiology Team, CDC; Guinea Interministerial Committee for Response Against the Ebola Virus; World Health Organization; CDC Guinea Response Team; Liberia Ministry of Health and Social Welfare; CDC Liberia Response Team; Sierra Leone Ministry of Health and Sanitation; CDC Sierra Leone Response Team; Viral Special Pathogens Branch, National Center for Emerging and Zoonotic Infectious Diseases, CDC; Centers for Disease Control and Prevention (CDC). Update: Ebola virus disease epidemic - West Africa, February 2015. MMWR Morb Mortal Wkly Rep 2015;64:186-7.

18. U.S. Department of Helath and Human Services. Centers for Disease Control and Prevention; 2015.

19. Bochennek K, Wittekindt B, Zimmermann SY, Klingebiel T. More than mere games: A review of card and board games for medical education. Med Teach 2007;29:941-8.

20. Gutierrez AF. Development and effectiveness of an educational card game as supplementary material in understanding selected topics in biology. CBE Life Sci Educ 2014;13:76-82.

21. Su T, Cheng MT, Lin SH. Investigating the effectiveness of an educational card game for learning how human immunology is regulated. CBE Life Sci Educ 2014;13:504-15.

22. Boeker M, Andel P, Vach W, Frankenschmidt A. Game-based e-learning is more effective than a conventional instructional method: A randomized controlled trial with third-year medical students. PLoS One 2013;8:e82328.

23. Donohoe KL, Mawyer TM, Stevens JT, Morgan LA, Harpe SE. An active-learning laboratory on immunizations. Am J Pharm Educ 2012;76:198.

24. Peffer ME, Beckler ML, Schunn C, Renken M, Revak A. Science classroom inquiry (SCI) simulations: A novel method to scaffold science learning. PLoS One 2015;10:e0120638.

25. Rowe MP, Gillespie BM, Harris KR, Koether SD, Shannon LJ, Rose LA. Redesigning a General Education Science Course to Promote Critical Thinking. CBE Life Sci Educ 2015;14. pii: Ar30.

26. Stone EM. Guiding students to develop an understanding of scientific inquiry: A science skills approach to instruction and assessment. CBE Life Sci Educ 2014;13:90-101. 


\section{Appendix}

Appendix 1: Introductory dungeons and vaccines.

\section{"Introductory Dungeons and Vaccines (D\&V)"}

Welcome to Dungeons and Vaccines, the first roleplaying game in which you are a character in a world where people interact with pathogenic organisms and defend themselves with the magical elixirs known as vaccines, a world not unlike our very own. On the cards you have received, you will find your character's origins (demographics), strengths (vaccinations), and weaknesses (infections). You will use this information to navigate this mystical world, where you will interact with other characters to see who will live, who will die, and who will get sick.

In today's game, we will play through 8 scenarios that reflect the vaccination rate, mortality, communicability, vaccine effectiveness, duration of infectivity, and demographic influence of 4 different diseases.

Gameplay is conducted in rounds, and each round consists of a series of steps. At the beginning of each round, follow the procedure below:

- Examine your card, make note of your infection status (indicated by a green star) and vaccination status (indicated by a red star). Determine the result of your infection status:

a. If you are not infected, role your die 3 times. If the sum of your rolls is 3, you die (because you know, you could always get hit by a bus). Remove yourself from the game and wait for the next scenario.

b. If you are infected, roll your die 3 times and calculate the sum of the rolls.

c. Based on the attached rubric, determine whether you recover from the disease, die from the disease, or remain infected

i. If you recover, remove your green star and place a blue star on your card.

ii. If you die remove yourself from the game by standing in the corner and wait for the next scenario.

- $\quad$ Turn to someone at your table and prepare to battle.

a. If neither of you are infected, roll each of your die 2 times (4 total rolls). If the sum of your rolls is a 4 then congratulations! You fell in love and got married.

b. If both of you are infected, roll each of your die 2 times (4 total rolls). If the sum of your rolls is a 24 then mazel tov! You decided to go into business with each other cooking and distributing methamphetamines in order to leave your families with enough money in case you ultimately succumb to this disease.

c. If one of you is infected, roll each of your die 2 times (4 total rolls).

i. Based on the attached rubric, determine if the disease has been transmitted by calculating the sum of your combined rolls and your vaccination/recovery status.

ii. If you become infected, indicate this change in status by placing a green star on your card. You now have the possibility of transmitting the infection to someone else.

- Repeat steps 1-2, making each pairwise interaction at your table (e.g. if there are 6 people at your bench, you will carry out steps 1 and 2 a total of 5 times, once for each other person at your bench, interacting with a new person each time).

- After all pairwise interactions have been completed at your table, the individuals with an odd number on their cards will move to the next table in a clockwise fashion. Individuals with an even number on their cards will stay put. Repeat each new pairwise interaction.

- Continue the process of making pairwise interactions and moving tables until you have made it back to your original table.

- After the completion of each scenario, fill out the appropriate table corresponding to your character's fate. 


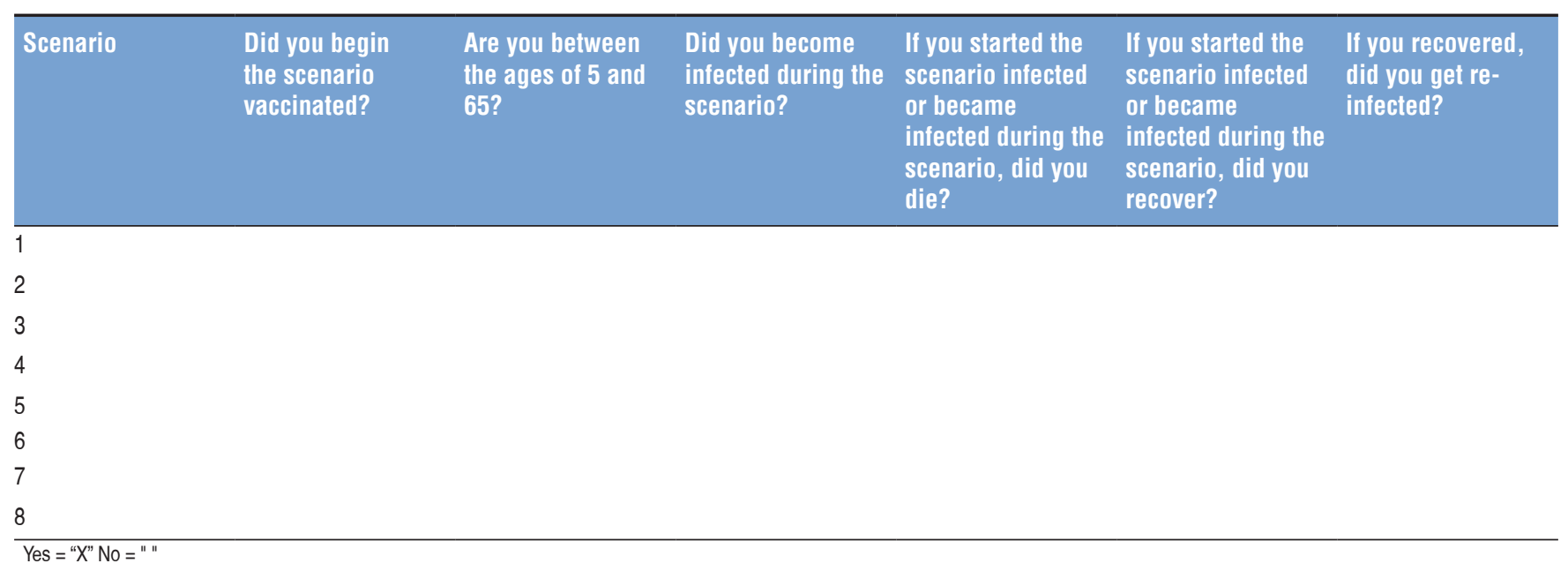

\section{PATHOGEN}

\begin{tabular}{lll}
\hline Influenza virus $\quad$ Measles virus & B. pertussis & Ebola virus
\end{tabular}

\section{STEP 1}

\begin{tabular}{|c|c|c|c|c|c|}
\hline \multirow{2}{*}{\multicolumn{2}{|c|}{5 years old }} & 7 = death & 4 = death & $8=$ death & 11 or less $=$ death \\
\hline & & 8 or $14=$ recover & 5 or $8=$ recover & 4 or 7 = recover & 15 or $18=$ recover \\
\hline \multirow{2}{*}{\multicolumn{2}{|c|}{$5<$ years old $<65$}} & $6=$ death & 4 = death & $5=$ death & 11 or less $=$ death \\
\hline & & 8 or $14=$ recover & 5 or $8=$ recover & 4 or $7=$ recover & 15 or $18=$ recover \\
\hline \multirow{2}{*}{\multicolumn{2}{|c|}{65 years old 8 or $14=$ recover }} & 7 = death & 4 = death & $5=$ death & 11 or less $=$ death \\
\hline & & 8 or $14=$ recover & 5 or $8=$ recover & 4 or 7 = recover & 15 or $18=$ recover \\
\hline \multicolumn{6}{|l|}{ STEP 2} \\
\hline \multirow[t]{3}{*}{ Transmission } & If vaccinated & 9 or less & 8 or less & 10 or less & 7 or less \\
\hline & If unvaccinated & 11 or less & 18 or less & 16 or less & 9 or less \\
\hline & If recovered ${ }^{*}$ & 22 or more & No number & 24 & No number \\
\hline
\end{tabular}

${ }^{*}$ Recovered trumps vaccinated

\section{Group \#}

In this part of the lab you will use a computer model of vaccine-preventable disease transmission to test hypotheses regarding herd immunity.

Start by opening the file containing the model in Excel (D2L, IdEALS II, Content, Lab 14). You will probably get the following error message:

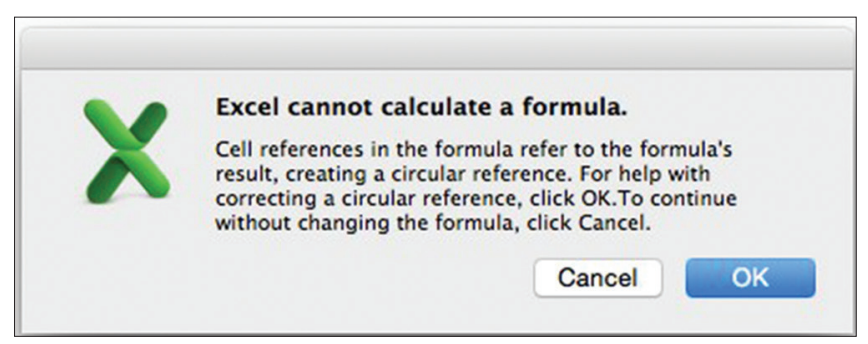

Click "Cancel”

Within Excel, go to Preferences !Calculations

Change "Calculate sheets" to "Manually"

Click on the box that says "Limit iteration", then enter a "1" for "Maximum iterations" and click "OK" 


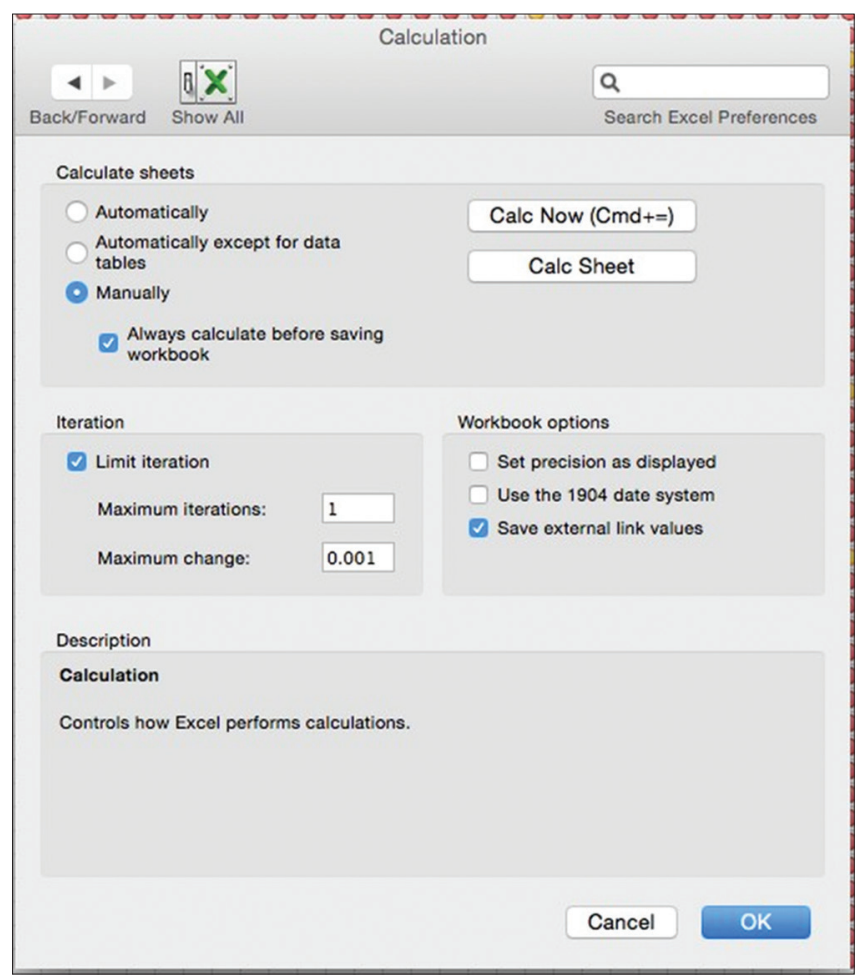

Now you should be ready to model the first pathogen: Influenza Virus

Enter the following information on the left hand side of the spreadsheet:

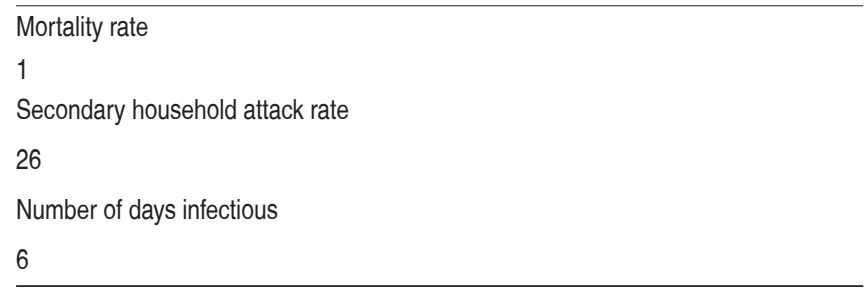

Now reset the board by entering "0" below the cell labeled "reset" and then pressing F9 for Windows, and "Command-Equal sign" for OSX.

To begin the simulation, change the mode by entering a "1" below the cell labeled "reset". Now every time you press F9 (Windows) or "Command-Equal sign" (OSX), you will advance the simulation one step.

For each simulation, advance the model until "\# infected" equals 0.

Once "\# infected" equals 0 , record all the pertinent information in the table provided.

The initial settings I gave you above represent the estimates from last year's flu season. Systematically alter "\% vaccinated" and "vaccine effectiveness" and record the results:

From January 1 to April 10, 2015, 159 people from 18 states and the District of Columbia were reported to have measles. Most of these cases [117 cases (74\%)] are part of a large, multi-state outbreak linked to an amusement park in California. The United States experienced a record number of measles cases during 2014, with 668 cases from 27 states reported to CDC's National Center for Immunization and Respiratory Diseases (NCIRD). This is the greatest number of cases since measles elimination was documented in the U.S. in 2000. 


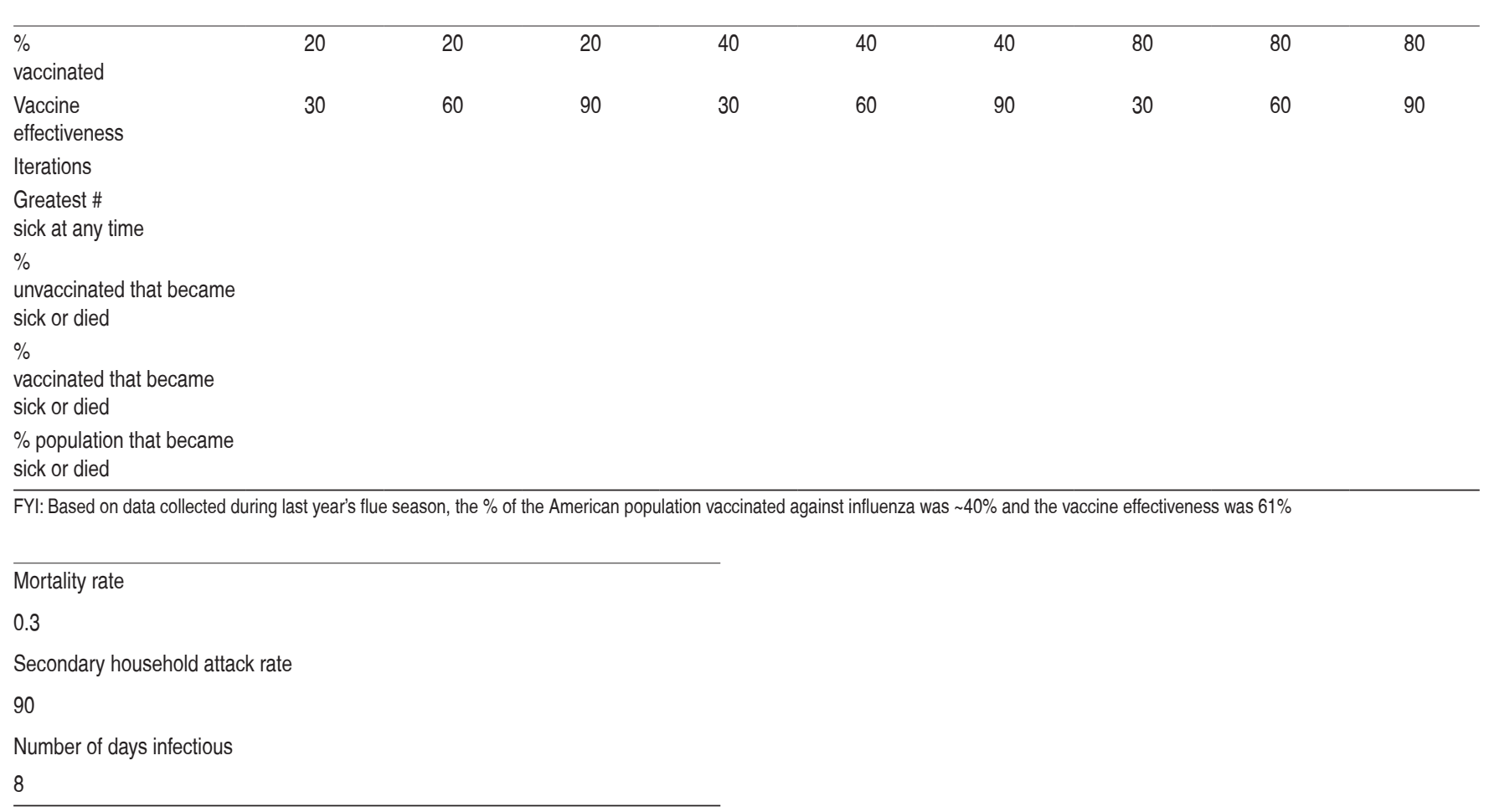

The measles vaccine confers remarkable protection against the virus. Its effectiveness has been estimated at $\sim 95 \%$.

What is the lowest percentage of the population that must be immunized to confer protection to at least $90 \%$ of the unvaccinated population? Record your results in the following table:

\begin{tabular}{l} 
\% \\
vaccinated \\
Vaccine effectiveness \\
Iterations \\
Greatest \# \\
sick at any time \\
$\%$ \\
unvaccinated that became \\
sick or died \\
$\%$ \\
vaccinated that became \\
sick or died \\
$\%$ population that became \\
sick or died \\
\hline Mortality rate \\
0.5 \\
Secondary household attack rate \\
80 \\
Number of days infectious \\
\hline
\end{tabular}

In $2012,48,277$ cases of pertussis (whooping cough) were reported in the U.S., but many more go undiagnosed and unreported. This is the most number of cases reported in the U.S. since 1955 when 62,786 cases were reported.

What is the lowest combination of vaccination rate and vaccine effectiveness required to protect at least $90 \%$ of the unvaccinated population? Record your results in the following table: 


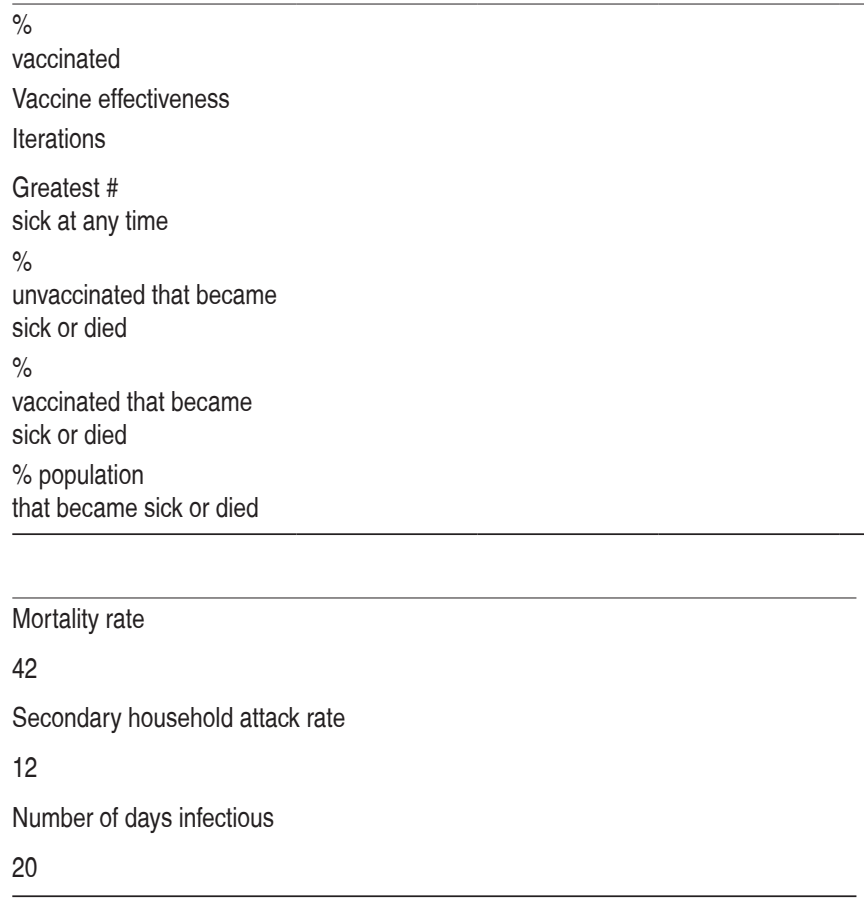

The 2014 Ebola epidemic is the largest in history, affecting multiple countries in West Africa. Two imported cases, including one death, and two locally acquired cases in healthcare workers have been reported in the United States. CDC and partners are taking precautions to prevent additional cases of Ebola in the United States.

Many groups are currently developing vaccines to combat Ebola, but only two have been tested in humans so far. GSK/National Institute of Allergy and Infectious Disease have developed CAd3- ZEBOV, a live-attenuated chimpanzee adenovirus variant engineered to express Ebola glycoproteins. Merck/Public Health Agency of Canada have developed VSV-EBOV, a live-attenuated variant of vesicular stomatitis virus engineered to express Ebola glycoproteins.

For either of these vaccines to be successful, they must adequately protect the population. What is the lowest combination of vaccination rate and vaccine effectiveness required to protect at least $90 \%$ of the total population? Record your results in the following table:

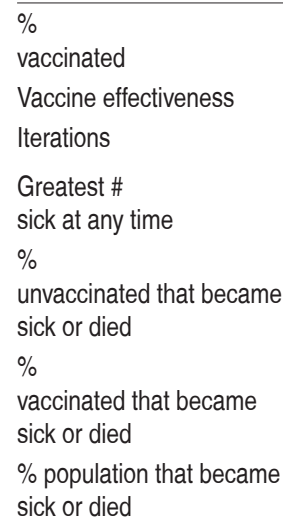

